OPEN ACCESS

Edited by:

Shervin Assari,

University of Michigan,

United States

Reviewed by:

Taiwo Lateef Sheikh,

Federal Neuropsychiatric Hospital,

Nigeria

Leandro Da Costa Lane Valiengo,

University of São Paulo, Brazil

*Correspondence:

Shih-Wei Lai

wei@mail.cmuh.org.tw

Specialty section: This article was submitted to Public Mental Health, a section of the journal

Frontiers in Psychiatry

Received: 05 August 2017 Accepted: 31 October 2017 Published: 13 November 2017

Citation:

Cheng K-C, Liao K-F, Lin C-L and Lai S-W (2017) Increased Risk of Pulmonary Tuberculosis in Patients with Depression:

A Cohort Study in Taiwan.

Front. Psychiatry 8:235

doi: 10.3389/fpsyt.2017.00235

\section{Increased Risk of Pulmonary Tuberculosis in Patients with Depression: A Cohort Study in Taiwan}

\author{
Kao-Chi Cheng ${ }^{1,2}$, Kuan-Fu Liao ${ }^{3,4,5}$, Cheng-Li Lin ${ }^{1,6}$ and Shih-Wei Lai ${ }^{1,2 *}$ \\ 'College of Medicine, China Medical University, Taichung, Taiwan, ${ }^{2}$ Department of Family Medicine, China Medical \\ University Hospital, Taichung, Taiwan, ${ }^{3}$ Department of Internal Medicine, Taichung Tzu Chi General Hospital, Taichung, \\ Taiwan, ${ }^{4}$ College of Medicine, Tzu Chi University, Hualien, Taiwan, ${ }^{5}$ Graduate Institute of Integrated Medicine, China Medical \\ University, Taichung, Taiwan, ${ }^{6}$ Management Office for Health Data, China Medical University Hospital, Taichung, Taiwan
}

Background/objective: Tuberculosis (TB) and depression were major public health issues worldwide and the mutual causative relationships between them were not exhaustive. This study was performed to explore the association between depression, comorbidities, and the risk of pulmonary TB in Taiwan.

Methods: The cohort study used the database of the Taiwan National Health Insurance Program. The depression group included 34,765 subjects aged 20-84 years with newly diagnosed depression from 2000 to 2012, and the non-depression group included 138,187 randomly selected subjects without depression. Both depression and nondepression groups were matched with respect to sex, age, and comorbidities. We explored the incidence of pulmonary TB at the end of 2013 in both the groups and used multivariable Cox proportional hazards regression model to explore the hazard ratio $(\mathrm{HR})$ and $95 \%$ confidence interval $(\mathrm{Cl})$ for the risk of pulmonary TB associated with depression.

Results: The overall incidence of pulmonary TB was 1.16-fold greater in the depression group than that in the non-depression group (1.52 vs. 1.31 per 1,000 person-years, 95\% Cl 1.12, 1.21). The multivariable Cox proportional hazards regression analysis revealed that the adjusted HR of pulmonary TB was 1.15 for the depression group (95\% Cl 1.03, 1.28), compared with the non-depression group.

Conclusion: Depression is associated with 1.15-fold increased hazard of pulmonary TB in Taiwan.

Keywords: epidemiology, cohort study, depression, pulmonary tuberculosis, comorbidities

\section{INTRODUCTION}

Tuberculosis (TB) is a major public health issue with a relatively high incidence and prevalence. It is also a chronic infectious multi-systemic disease which has burdened the socioeconomic and health-care aspect in the past few decades. According to the World Health Organization (WHO) report, at least 10.4 million people demonstrated new incidents of TB worldwide in 2014 (1). Half of 
all the global new cases of TB occurred in some developing Asian countries, such as Bangladesh, China, India, and Pakistan (2). In Taiwan, the annual incidence was 63.7 and 53 cases per 100,000 person-years in 2006 and 2012 (3, 4). Meanwhile, we observed the declined trend of TB incidence over the past 50 years in Taiwan after efforts of Taiwan Centers for Disease Control (CDC) (5). All efforts for recent decades decreasing incidence of $\mathrm{TB}$ in Taiwan by Taiwan CDC, including directly observed treatment, short course (DOTS) for sputum smear-positive patients, DOTSplus strategy for multidrug resistance tuberculosis patients and profound treatment for latent TB children. After all control measurements mentioned above, in 2013 alone, there were 54.5 new diagnosed cases and 2.8 deaths per 100,000 populations in Taiwan (6). The first-line medications for TB include rifampicin, isoniazid, pyrazinamide, and ethambutal, the treatment duration was suggested 6 months in general. Until 2009 in Taiwan, the treatment success rate is up to $87 \%$ (7).

In addition to developing countries, $4-6 \%$ of the population in United States have latent infections of TB (8). Previous studies have demonstrated multiple risk factors associated with pulmonary $\mathrm{TB}$, including chronic obstructive pulmonary disease (COPD), pneumoconiosis $(9,10)$, chronic kidney disease (CKD), diabetes mellitus (DM), and human immunodeficiency virus (HIV) (11). Male gender, old age, tobacco smoking, and alcohol consumption have also been shown to be related with pulmonary TB $(12,13)$.

Depression is the second leading cause of disease burden, accounting for $3.8 \%$ of the total disability-adjusted life year in the year 2010, and it causes the largest amount of non-fatal burden which accounts for almost $8.2 \%$ of all total years lived with disability worldwide (14). At the same time, we found that the prevalence of depression ranged from 1.2 to $26 \%$ in Taiwan's community studies in 2005 and in large scale, more 10 thousands respondents study $(15,16)$. Although $1.7 \%$ in the 1980 s, the incidence rate of depression in elderly raised up to $19.7 \%$ gradually. Furthermore, adults 65 years and older accounts for $10.53 \%$ of all populations (17), will be a critical public issue in Taiwan.

Among the various organs and tissues in humans, lungs are predominantly affected by TB infection. Awareness about depression and its role in chronic disorders such as rheumatoid arthritis and COPD has increased over the years (18). Psychiatric illness may develop subsequent to TB infection, and mood disorders seem to be particularly common in TB populations compared to populations infected with other chronic diseases $(6,8,19)$. Due to the frequent comorbidity of TB and associated mood disorders, particularly depression, it is very important for general physicians and psychiatric specialists to be mindful of depression while treating patients with TB. Although depression has been shown to be common in patients with TB (20-22), Up to this day, the mechanism and relationships between depression and pulmonary TB is complex and elusive. In the past few decades, to the best of our knowledge, no study as yet has examined the causative relationship between depression and pulmonary TB in Taiwan. Thus, we aimed to determine the presence of depression in patients suffering from pulmonary TB in Taiwan.

\section{MATERIALS AND METHODS}

\section{Design and Data Source}

Taiwan is a sovereign and independent country with more than 23 million residents (23-34). This population-based cohort study used the database of the Taiwan National Health Insurance Program. This insurance program began in March 1, 1995, and it has covered about $99 \%$ of 23 million residents living in Taiwan (35). The details of the program have been well documented in previous studies (36-40). This study was approved by the Ethics Review Board of China Medical University in Taiwan (CMUH-104-REC2-115).

\section{Participants}

We selected subjects aged 20-84 years with newly diagnosed depression from 2000 to 2012 into the depression group [the International Classification of Diseases (ICD) 9th Revision, ICD-9 codes 296.2, 296.3, 300.4, and 311]. To increase the statistical power, four subjects without depression were randomly selected, for each subject with depression, into the non-depression group. The index date was defined as the date depression was diagnosed. Both depression and non-depression groups were matched with respect to sex, age (every 5-year interval), and comorbidities.

\section{Comorbidities}

The following comorbidities that could be potentially related to pulmonary TB were included: alcohol-related disease, asbestosis, CKD, COPD, DM, HIV infection, gastrectomy, pneumoconiosis, splenectomy, and chronic liver diseases, including cirrhosis, hepatitis B infection, hepatitis $\mathrm{C}$ infection, and other chronic hepatitis. All comorbidities were diagnosed with ICD-9 codes. The accuracy of ICD-9 codes has been examined in previous studies $(41-56)$.

\section{Major Outcome}

The major outcome was a new diagnosis of pulmonary TB (ICD-9 codes 010, 011, 012, and 018) during the follow-up period. All study subjects were followed up with until they were diagnosed with pulmonary TB or to the end of 2013.

\section{Statistical Analysis}

The distributions of sex, age, and comorbidities were compared between the depression and non-depression groups using the chi-square and Fisher-exact test for categorized variables, and the $t$-test for continuous variables. The incidence of pulmonary TB was estimated as the number of pulmonary TB events identified during the follow-up period, divided by the total follow-up person-years for each group. Initially, all variables were included in a univariable model. Next, variables found to be statistically significant in the univariable model were further included in the multivariable model. The multivariable Cox proportional hazards regression model was used to estimate the hazard ratio (HR) and 95\% confidence interval (CI) for the risk of pulmonary TB associated with depression and other comorbidities. All analyses were performed using the SAS 9.2 (SAS Institute 
Inc., Carey, NC, USA). The results were considered statistically significant when two-tailed $P$ values were less than 0.05 .

\section{RESULTS}

\section{Baseline Characteristics of the Study Population}

Baseline characteristics of the study population have been depicted in Table 1 . There were 34,765 subjects in the depression group and 138,187 subjects in the non-depression group, with

TABLE 1 | Baseline characteristics between depression group and nondepression group.

\begin{tabular}{|c|c|c|c|c|c|}
\hline \multirow[b]{2}{*}{ Characteristic } & \multicolumn{2}{|c|}{$\begin{array}{c}\text { Non-depression } \\
(N=138,187)\end{array}$} & \multicolumn{2}{|c|}{$\begin{array}{l}\text { Depression } \\
(N=34,765)\end{array}$} & \multirow[b]{2}{*}{$P$ value } \\
\hline & $n$ & $\%$ & $n$ & $\%$ & \\
\hline Sex & & & & & 0.96 \\
\hline Female & 52,072 & 37.7 & 13,105 & 37.7 & \\
\hline Male & 86,115 & 62.3 & 21,660 & 62.3 & \\
\hline Age group (years) & & & & & 0.61 \\
\hline 20-39 & 49,893 & 36.1 & 12,453 & 35.8 & \\
\hline $40-64$ & 62,652 & 45.3 & 15,834 & 45.6 & \\
\hline $65-84$ & 25,642 & 18.6 & 6,478 & 18.6 & \\
\hline Age (years), mean (SD) ${ }^{c}$ & 47.6 & $(16.6)$ & 47.9 & $(16.5)$ & 0.002 \\
\hline $\begin{array}{l}\text { Follow-up period (years), } \\
\text { mean }(\mathrm{SD})^{\mathrm{c}}\end{array}$ & 8.30 & $(3.37)$ & 8.21 & $(3.41)$ & $<0.001$ \\
\hline \multicolumn{6}{|l|}{ Baseline comorbidities } \\
\hline Alcohol-related disease & 9,632 & 6.97 & 2,516 & 7.24 & 0.08 \\
\hline Asbestosis $^{b}$ & 8 & 0.01 & 6 & 0.02 & 0.03 \\
\hline Chronic kidney disease & 3,076 & 2.23 & 839 & 2.41 & 0.04 \\
\hline Chronic liver disease & 24,786 & 17.9 & 6,314 & 18.2 & 0.33 \\
\hline $\begin{array}{l}\text { Chronic obstructive } \\
\text { pulmonary disease }\end{array}$ & 16,874 & 12.2 & 4,330 & 12.5 & 0.21 \\
\hline Diabetes mellitus & 8,886 & 6.43 & 2,304 & 6.63 & 0.18 \\
\hline $\begin{array}{l}\text { Human immunodeficiency } \\
\text { virus infection }\end{array}$ & 140 & 0.10 & 52 & 0.15 & 0.02 \\
\hline Gastrectomy & 273 & 0.20 & 109 & 0.31 & 0.001 \\
\hline Pneumoconiosis & 666 & 0.48 & 212 & 0.61 & 0.003 \\
\hline Splenectomy & 60 & 0.04 & 27 & 0.08 & 0.01 \\
\hline
\end{tabular}

Data are presented as the number of subjects in each group with percentages given in parentheses, or mean with SD given in parentheses.

${ }^{a}$ Chi-square test, ${ }^{b}$ Fisher-exact test, and ${ }^{c t}$-test comparing subjects with and without depression. a similar distribution of sex. The mean ages (SD) of the study subjects were 47.9 (16.5) and 47.6 (16.6) years for the depression and non-depression group, respectively. The depression group had higher proportion of asbestosis, CKD, HIV infection, gastrectomy, pneumoconiosis, and splenectomy than that in the non-depression group (chi-square test, $P<0.05$ for all).

\section{Incidence of Pulmonary TB in the Study Population Stratified by Sex and Age}

The overall incidence of pulmonary TB was 1.16 -fold greater in the depression group than that in the non-depression group (1.52 vs. 1.31 per 1,000 person-years, $95 \%$ CI 1.12, 1.21 ; Table 2 ). The incidence of pulmonary TB, as stratified by sex and age, was also higher in the depression group than in the non-depression group. The depression group with ages from 65 to 84 years had the highest incidence of pulmonary TB (4.88 per 1,000 personyears). The Kaplan-Meier model revealed that the depression group had a higher cumulative incidence of pulmonary TB than the non-depression group ( 1.68 vs. $1.50 \%$ at the end of follow-up; $P<0.001 ;$ Figure 1)

\section{Pulmonary TB Associated With Depression}

We then examined the risk of pulmonary TB associated with depression. Variables found to be statistically significant in the univariable model were further examined in the multivariable model. After adjusting for covariables, the multivariable Cox proportional hazards regression analysis revealed that the adjusted HR for pulmonary TB was 1.15 for the depression group $(95 \%$ CI $1.03,1.28)$ compared with the non-depression group (Table 3 ).

\section{Risk of Pulmonary TB Stratified by Depression and Comorbidities}

We also analyzed the risk of pulmonary TB stratified by depression and comorbidities. To reduce the potential confounding effects of comorbidities, we analyzed subjects without depression and without comorbidities. The adjusted HR of pulmonary TB was 1.37 for subjects with depression and without comorbidities (95\% CI 1.17, 1.62; Table 4). This finding indicates that

TABLE 2 | Incidence of pulmonary tuberculosis estimated by sex and age between depression group and non-depression group.

\begin{tabular}{|c|c|c|c|c|c|c|c|c|c|}
\hline \multirow[b]{2}{*}{ Variable } & \multicolumn{4}{|c|}{ Non-depression } & \multicolumn{4}{|c|}{ Depression } & \multirow[b]{2}{*}{$\begin{array}{c}\text { IRR }^{\text {b }}[95 \% \text { confidence } \\
\text { interval }(\mathrm{CI})]\end{array}$} \\
\hline & $N$ & Event & Person-years & Incidence ${ }^{a}$ & $N$ & Event & Person-years & Incidence $^{a}$ & \\
\hline All & 138,187 & 1504 & 1146,960 & 1.31 & 34,765 & 435 & 285,537 & 1.52 & $1.16(1.12,1.21)$ \\
\hline \multicolumn{10}{|l|}{ Sex } \\
\hline Female & 52,072 & 569 & 727,530 & 0.78 & 13,105 & 171 & 181,913 & 0.94 & $1.20(1.14,1.26)$ \\
\hline Male & 86,115 & 935 & 419,431 & 2.23 & 21,660 & 264 & 103,625 & 2.55 & $1.14(1.08,1.21)$ \\
\hline \multicolumn{10}{|c|}{ Age group (years) } \\
\hline 20-39 & 49,893 & 150 & 433,734 & 0.35 & 12,453 & 63 & 107,501 & 0.59 & $1.69(1.59,1.81)$ \\
\hline $40-64$ & 62,652 & 528 & 531,375 & 0.99 & 15,834 & 151 & 132,729 & 1.14 & $1.14(1.08,1.21)$ \\
\hline $65-84$ & 25,642 & 826 & 181,851 & 4.54 & 6,478 & 221 & 45,307 & 4.88 & $1.07(0.99,1.16)$ \\
\hline
\end{tabular}

ancidence: per 1,000 person-years.

bIRR (incidence rate ratio): depression vs. non-depression (95\% Cl). 


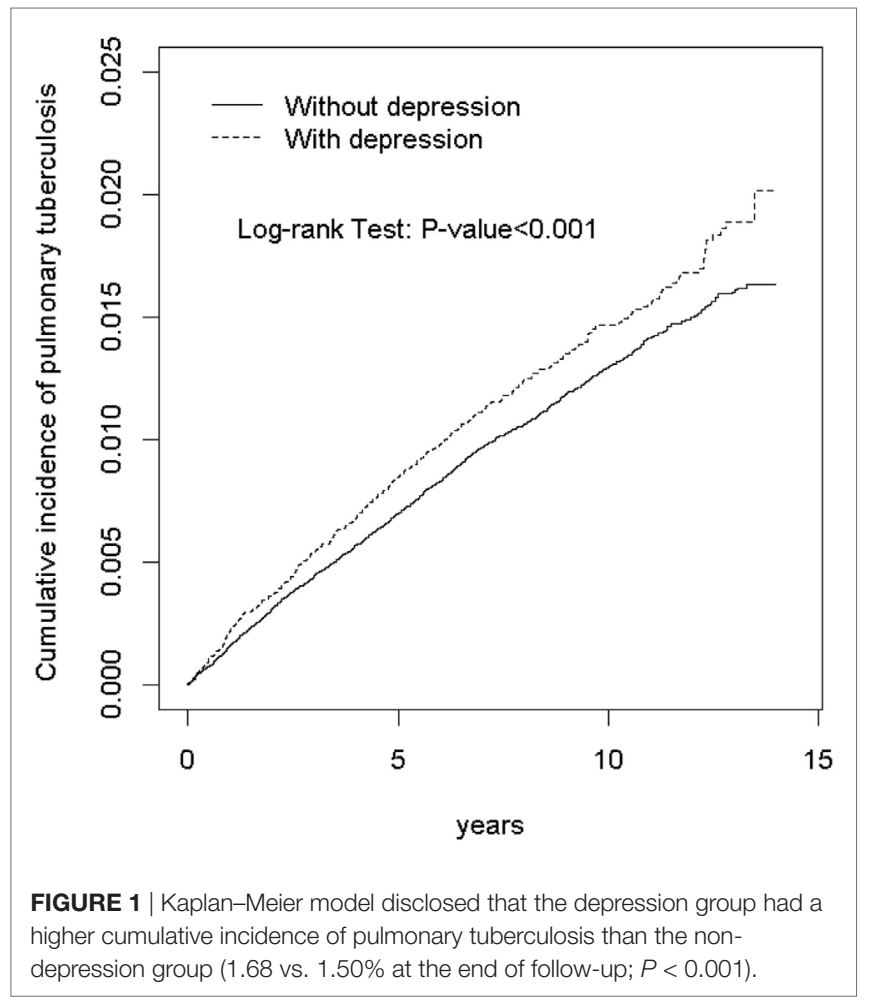

TABLE 3 | Cox model measured hazard ratio (HR) and 95\% confidence interval (Cl) of pulmonary tuberculosis (TB) associated with depression and comorbidities.

\begin{tabular}{lcc}
\hline & \multicolumn{1}{c}{ Crude } & Adjusted $^{\mathbf{a}}$ \\
\cline { 2 - 3 } Variable & HR (95\% Cl) & HR (95\% Cl) \\
\hline Sex (male vs. female) & $2.81(2.56,3.08)$ & $2.37(2.16,2.61)$ \\
Age (per 1 year) & $1.07(1.06,1.07)$ & $1.06(1.05,1.06)$ \\
Depression & $1.16(1.04,1.29)$ & $1.15(1.03,1.28)$ \\
Baseline comorbidities (yes vs. no) & & \\
Alcohol-related disease & $1.68(1.44,1.95)$ & $1.85(1.58,2.16)$ \\
Chronic kidney disease (CKD) & $2.99(2.44,3.66)$ & $1.19(0.97,1.46)$ \\
Chronic liver disease & $1.33(1.19,1.48)$ & $0.95(0.85,1.07)$ \\
Chronic obstructive pulmonary & $4.18(3.80,4.59)$ & $1.66(1.50,1.84)$ \\
disease (COPD) & & \\
Diabetes mellitus (DM) & $3.29(2.91,3.71)$ & $1.55(1.37,1.75)$ \\
Human immunodeficiency & $3.67(1.65,8.18)$ & $6.93(3.10,15.5)$ \\
virus (HIV) infection & & \\
Gastrectomy & $2.76(1.48,5.14)$ & $1.18(0.63,2.20)$ \\
Pneumoconiosis & $4.75(3.43,6.58)$ & $1.80(1.29,2.49)$ \\
\hline
\end{tabular}

aVariables found to be statistically significant in the univariable model were further examined in the multivariable model.

Adjusted for sex, age, alcohol-related disease, CKD, chronic liver disease, COPD, DM, HIV infection, gastrectomy, and pneumoconiosis.

There was no event of pulmonary TB among subjects with asbestosis, or splenectomy.

even in the absence of comorbidities, depression may have a unique role on the risk of pulmonary TB.

\section{DISCUSSION}

In this study, we examined the association between depression and pulmonary $\mathrm{TB}$, including relative comorbidities.
TABLE 4 | Risk of pulmonary tuberculosis stratified by depression and comorbidities.

\begin{tabular}{|c|c|c|c|c|c|}
\hline Variable & & Event & $\begin{array}{l}\text { Person- } \\
\text { years }\end{array}$ & Incidence $^{a}$ & $\begin{array}{c}\text { Adjusted hazard } \\
\text { ratio }^{\mathrm{b}}(95 \% \mathrm{Cl})\end{array}$ \\
\hline $\begin{array}{l}\text { Non- } \\
\text { depression }\end{array}$ & $\begin{array}{l}\text { No } \\
\text { comorbidity }^{c}\end{array}$ & 574 & 781086 & 0.73 & 1 (reference) \\
\hline $\begin{array}{l}\text { Non- } \\
\text { depression }\end{array}$ & $\begin{array}{l}\text { Any } \\
\text { comorbidityc }\end{array}$ & 930 & 365874 & 2.54 & $1.82(1.63,2.03)$ \\
\hline Depression & $\begin{array}{l}\text { No } \\
\text { comorbidity }^{c}\end{array}$ & 194 & 193431 & 1.00 & $1.37(1.17,1.62)$ \\
\hline Depression & $\begin{array}{l}\text { Any } \\
\text { comorbidity }^{c}\end{array}$ & 241 & 92107 & 2.62 & $1.87(1.60,2.17)$ \\
\hline
\end{tabular}

alncidence rate: per 1,000 person-years.

${ }^{b}$ Adjusted for sex and age.

${ }^{\mathrm{C} C o m o r b i d i t i e s ~ i n c l u d i n g ~ a l c o h o l-r e l a t e d ~ d i s e a s e, ~ c h r o n i c ~ k i d n e y ~ d i s e a s e, ~ c h r o n i c ~}$ liver disease, chronic obstructive pulmonary disease, diabetes mellitus, human immunodeficiency virus infection, gastrectomy, and pneumoconiosis.

We found that the mean age of depression group was higher than the non-depression group. In addition, the depression group showed a higher proportion of asbestosis, CKD, HIV infection, gastrectomy, pneumoconiosis, and splenectomy than the non-depression group. By the way, the comorbidities listed in our study might indicate the common ones of Taiwanese, not represent of all ethical groups worldwide. Race and ethnicity may shape the links between comorbid psychiatric disorders and chronic medical conditions. So, we suggest that future studies should put emphasis on the understanding why associations between physical and mental health vary among race and ethnic groups (57). A possible explanation is the lower immune status in the elderly. It has been previously shown that the decreased immune function associated with depression is related to increased susceptibility to immune-mediated diseases, such as cancer, infectious diseases, and autoimmune diseases (58). Furthermore, previous articles have revealed that diabetes, splenectomy, appendectomy, and gastrectomy correlate with the increasing risk of pulmonary TB in Taiwan, compatible with the results of our study $(3,48,59,60)$.

We show that the adjusted HR of pulmonary TB is 1.15 for the depression group (95\% CI 1.03, 1.28) compared with the non-depression group. Although previous studies have shown definite association between them worldwide $(8,20,22)$, including studies published in Nigeria 8 years ago $(61,62)$, there were no related studies exploring the relationship between depression and TB in Taiwan. Unlike previous similar studies worldwide, we tried to explain two-way causative relationship between TB and depression. Patients with TB were usually considered related to higher frequency depression due to several reasons mentioned below. They usually isolated from their families, less free due to the complication rate of anti-TB medication and might experience unfair viewpoints form society $(6,19)$. Furthermore, during the treatment course, they always meet difficulties in financial aspect (63). On the contrary, TB is considered to be more common among individuals with mood disorders as opposed to those with other psychiatric illnesses.

Some past literature revealed that depression patients were more prone to TB infection, the same result in our study, since they are easily to be exposed to risk factors for the disease 
$(8,64)$. The major risk factors was discussed in previous literature, such as homeless (65), emigration from a country in which TB is endemic (22). Other minor ones, male gender, drug and alcohol abuser, and previous psychiatric hospitalizations were also noted in published articles (8), which failed to comply with routine TB treatment course, thus result in poor compliance and higher frequency for TB. Although we discussed mutual causative consequences profound, unfortunately, we still could not provide accurate and enough evidence that most risk factors mentioned above whether or not enrolled in our study due to innate limitation. Otherwise, in our study, potential bias and selection bias were still inevitable, future studies should add consideration that the prevalence and incidence of depression or pulmonary $\mathrm{TB}$ correlates with severity and duration for increasing the accuracy of studies, similar to previous review article $(19,66)$. Most of the studies do not mention how to be mindful of the clinical manifestation of depression in the earliest stage of TB and the mutual causative consequences. Thus, we used a large scale, long-term cohort study for exploring the link between depression and the risk of TB.

We hypothesized that lower immune response status may be the key point to understand the association between depression and pulmonary TB. Depression is usually found in elderly population, accompanied with dysphoria, insomnia, and bad mood along with poor appetite $(67,68)$. Exposure to these morbidities for a long time may result in incomplete and non-comprehensive immunity for protection against micro-organisms, including Mycobacterium tuberculosis. In addition, poor appetite and depression results in malnutrition and cachexia. Malnutrition profoundly affects cell-mediated immunity, which has been shown to be the principle host defense against TB (69) in humans and experimental animals. It was also shown by Trenton et al. that $\mathrm{TB}$ tends to be isolated in the lungs or other single sites in the hosts with more competent immunity. If the immune system is less robust, the disease tends to proliferate to extrapulmonary sites, including kidneys, bones, or meninges, which may result in subsequent infections of TB (8).

Another possible explanation may be the decreased treatment compliance of pulmonary TB. A large scale retrospective cohort study revealed that patients with $\mathrm{TB}$ have a high rate of relapse due to poor medication compliance, psychiatric disorders, alcoholism, and drug addiction (70). Some other psychological issues, such as stigma, isolation, social or family support, and helplessness were also mentioned in previous literature, thus lowered the treatment compliance (19). Patients with depression are usually in a bad mood, easily forgetting scheduled plans, including routine medication for pulmonary TB. Therefore, it may be important to assume that prevention and prompt treatment of psychological disorders in TB patients may be helpful to increase treatment compliance and reduce the relapse of TB.

Finally, the adjusted HR of pulmonary TB was 1.37 for subjects with depression alone and without comorbidities (95\% CI 1.17, 1.62; Table 4). This finding shows that depression has an independent role in the risk of pulmonary TB. Thus, general physicians and psychiatrists should pay more attention in evaluating pulmonary $\mathrm{TB}$ along with the clinical manifestation of depression.

\section{Limitation}

First, the insurance claims that the data do not provide definite measurement for the clinical diagnosis of depression, such as by DSM-V, and we were unable to evaluate depression by the coding and clinical condition assessment of physicians. More accurate tools for the diagnosis of pulmonary TB, such as chest radiographic films or sputum culture, are necessary. Therefore, the actual number of pulmonary TB in depression population may be underestimated or overestimated. Second, as the diagnosis of depression and pulmonary TB requires long-term observation for its clinical manifestation, the shorter observation period in our study may have been insufficient to estimate the pulmonary TB risk compared with a full course of natural history in clinics or hospitals. The associated variable measures may thus be underestimated. Also, this study included comorbidity information at the baseline, prior to the date of establishing the study cohorts. Thus, comorbidities developed during the follow-up period may vary leading to variabilities in the estimation of pulmonary $\mathrm{TB}$ risk. Finally, we found no literature for herd immunity of TB in Taiwan, and socioeconomic status level (6) was not enrolled in our study due to study design and innate limitation, might distortion.

\section{Strength}

One of the primary strength of this study is the set of ICD-9 codes, which has been previously validated in published studies (41-56). Also, the long-term observation period from 2000 to 2012 allowed for more credibility compared with other similar studies to propose physical mechanisms and plausible hypotheses. Finally and the most important, we tried explained mutual biological and psychological mechanism between depression and pulmonary TB.

\section{CONCLUSION}

We evaluated the risk of pulmonary TB in association with depression and several medical comorbidities in the Taiwanese population using representative population-based data. We demonstrated that patients with depression are at a significantly higher risk of pulmonary TB than those without depression. Other comorbidities may also interact with depression and have a synergistic effect on the risk of pulmonary TB. As depression and pulmonary TB are popular disorders, they have been studied in many other countries for the past few decades. Further studies are needed for patients with depression not only to prevent its clinical exacerbation but also to decrease the possibility of pulmonary TB infection before initialization of depression. The understanding of comorbidities and other psychological factors may yield important preventive and detective methods for reducing the pulmonary TB infection rate. We hope that this study will provide information for earlier intervention and prevention of pulmonary TB in patients with depression worldwide.

\section{AUTHOR CONTRIBUTIONS}

K-CC and K-FL planned and conducted this study. They participated in the data interpretation and revised the article. 
C-LL conducted the data analysis and revised the article. S-WL planned and conducted this study. He contributed to the conception of the article, initiated the draft of the article, and revised the article, and contributed equally to the article.

\section{ACKNOWLEDGMENTS}

This study was supported in part by Taiwan Ministry of Health and Welfare Clinical Trial Center (MOHW106-TDU-

\section{REFERENCES}

1. Zumla A, George A, Sharma V, Herbert RH; Baroness Masham of Ilton, Oxley A, et al. The WHO 2014 to go. Lancet Glob Health (2015) 3(1):e10-2. doi:10.1016/S2214-109X(14)70361-4

2. World Health Organization. Fact Sheet about Tuberculosis, 2007.

3. Huang SF, Li CP, Feng JY, Chao Y, Su WJ. Increased risk of tuberculosis after gastrectomy and chemotherapy in gastric cancer: a 7-year cohort study. Gastric Cancer (2011) 14(3):257. doi:10.1007/s10120-011-0037-1

4. Chung W-S, Yang M-C, Lee M-C. Costs and cost effectiveness of directly observed therapy short-course (DOTS) for pulmonary tuberculosis in Taiwan. J Med Health (2012) 1(1):33-45.

5. Lo H-Y, Chou P, Yang SL, Lee CY, Kuo HS. Trends in tuberculosis in Taiwan, 2002-2008. J Formos Med Assoc (2011) 110(8):501-10. doi:10.1016/ S0929-6646(11)60076-4

6. Shen TC, Wang CY, Lin CL, Liao WC, Chen CH, Tu CY, et al. People with tuberculosis are associated with a subsequent risk of depression. Eur J Intern Med (2014) 25(10):936-40. doi:10.1016/j.ejim.2014.10.006

7. Centers for Disease Control, Ministry of Health and Welfare, ROC (Taiwan). Taiwan Tuberculosis Control Report, 2013. Taiwan: Centers for Disease Control, Ministry of Health and Welfare (2013)

8. Trenton AJ, Currier GW. Treatment of comorbid tuberculosis and depression. Prim Care Companion J Clin Psychiatry (2001) 3(6):236. doi:10.4088/ PCC.v03n0610

9. Wu HP, Pan YH, Hua CC, Shieh WB, Jiang BY, Yu TJ. Pneumoconiosis and liver cirrhosis are not risk factors for tuberculosis in patients with pulmonary infection. Respirology (2007) 12(3):416-9. doi:10.1111/j.1440-1843.2007. 01033.x

10. Lee CH, Lee MC, Shu CC, Lim CS, Wang JY, Lee LN, et al. Risk factors for pulmonary tuberculosis in patients with chronic obstructive airway disease in Taiwan: a nationwide cohort study. BMC Infect Dis (2013) 13(1):194. doi:10.1186/1471-2334-13-194

11. Gupta S, Shenoy VP, Mukhopadhyay C, Bairy I, Muralidharan S. Role of risk factors and socio-economic status in pulmonary tuberculosis: a search for the root cause in patients in a tertiary care hospital, South India. Trop Med Int Health (2011) 16(1):74-8. doi:10.1111/j.1365-3156.2010.02676.x

12. Zevallos M, Justman JE. Tuberculosis in the elderly. Clin Geriatr Med (2003) 19(1):121-38. doi:10.1016/S0749-0690(02)00057-5

13. Corbett EL, Churchyard GJ, Clayton TC, Williams BG, Mulder D, Hayes RJ, et al. HIV infection and silicosis: the impact of two potent risk factors on the incidence of mycobacterial disease in South African miners. AIDS (2000) 14(17):2759-68. doi:10.1097/00002030-200012010-00016

14. Whiteford HA, Degenhardt L, Rehm J, Baxter AJ, Ferrari AJ, Erskine HE, et al. Global burden of disease attributable to mental and substance use disorders: findings from the Global Burden of Disease Study 2010. Lancet (2013) 382(9904):1575-86. doi:10.1016/S0140-6736(13)61611-6

15. Chiu HC, Chen CM, Huang CJ, Mau LW. Depressive symptoms, chronic medical conditions and functional status: a comparison of urban and rural elders in Taiwan. Int J Geriatr Psychiatry (2005) 20(7):635-44. doi:10.1002/ gps.1292

16. Liao SC, Chen WJ, Lee MB, Lung FW, Lai TJ, Liu CY, et al. Low prevalence of major depressive disorder in Taiwanese adults: possible explanations and implications. Psychol Med (2012) 42(6):1227-37. doi:10.1017/ S0033291711002364
B-212-113004), China Medical University Hospital, Academia Sinica Taiwan Biobank Stroke Biosignature Project (BM10601010036), Taiwan Clinical Trial Consortium for Stroke (MOST 106-2321-B-039-005), Tseng-Lien Lin Foundation, Taichung, Taiwan, Taiwan Brain Disease Foundation, Taipei, Taiwan, and Katsuzo and Kiyo Aoshima Memorial Funds, Japan. These funding agencies did not influence the study design, data collection and analysis, decision to publish, or preparation of the manuscript.

17. Lue B-H, Chen L-J, Wu S-C. Health, financial stresses, and life satisfaction affecting late-life depression among older adults: a nationwide, longitudinal survey in Taiwan. Arch Gerontol Geriatr (2010) 50:S34-8. doi:10.1016/ S0167-4943(10)70010-8

18. Kunik ME, Roundy K, Veazey C, Souchek J, Richardson P, Wray NP, et al. Surprisingly high prevalence of anxiety and depression in chronic breathing disorders. Chest (2005) 127(4):1205-11. doi:10.1016/S0012-3692(15) 34468-8

19. Pachi A, Bratis D, Moussas G, Tselebis A. Psychiatric morbidity and other factors affecting treatment adherence in pulmonary tuberculosis patients. Tuberc Res Treat (2013) 2013:489865. doi:10.1155/2013/489865

20. Aydin IO, Uluşahin A. Depression, anxiety comorbidity, and disability in tuberculosis and chronic obstructive pulmonary disease patients: applicability of GHQ-12. Gen Hosp Psychiatry (2001) 23(2):77-83. doi:10.1016/S01638343(01)00116-5

21. Natani GD, Jain NK, Sharma TN, Gehlot PS, Agrawal SP, Koolwal S, et al. Depression in tuberculosis patients: correlation with duration of disease and response to anti-tuberculosis chemotherapy. Indian J Tuberc (1985) 32:195-8.

22. McQuistion HL, Colson P, Yankowitz R, Susser E. Tuberculosis infection among people with severe mental illness. Psychiatr Serv (1997) 48(6):833-5. doi:10.1176/ps.48.6.833

23. Chan CY, Lien CH, Lee MF, Huang CY. Quercetin suppresses cellular migration and invasion in human head and neck squamous cell carcinoma (HNSCC). Biomedicine (Taipei) (2016) 6(3):10-5. doi:10.7603/s40681016-0015-3

24. Chang LC, Yu YL. Dietary components as epigenetic-regulating agents against cancer. Biomedicine (Taipei) (2016) 6(1):9-16. doi:10.7603/s40681-0160002-8

25. Chang WS, Liu LC, Hsiao CL, Su CH, Wang HC, Ji HX, et al. The contributions of the tissue inhibitor of metalloproteinase-1 genotypes to triple negative breast cancer risk. Biomedicine (Taipei) (2016) 6(1):23-8. doi:10.7603/ s40681-016-0004-6

26. Chao PC, Chuang HJ, Tsao LY, Chen PY, Hsu CF, Lin HC, et al. The Malnutrition Universal Screening Tool (MUST) and a nutrition education program for high risk cancer patients: strategies to improve dietary intake in cancer patients. Biomedicine (Taipei) (2015) 5(3):30-5. doi:10.7603/s40681-0150017-6

27. Chen HF, Wu KJ. Epigenetics, TET proteins, and hypoxia in epithelialmesenchymal transition and tumorigenesis. Biomedicine (Taipei) (2016) 6(1):1-8. doi:10.7603/s40681-016-0001-9

28. Ho TF, Chang CC. A promising "TRAIL" of tanshinones for cancer therapy. Biomedicine (Taipei) (2015) 5(4):23. doi:10.7603/s40681-015-0023-8

29. Hsieh TC, Wu YC, Sun SS, Yen KY, Kao CH. Treating hepatocellular carcinoma with ${ }^{90}$ Y-bearing microspheres: a review. Biomedicine (Taipei) (2016) 6(4):19. doi:10.7603/s40681-016-0019-Z

30. Huang YP, Chang NW. PPARalpha modulates gene expression profiles of mitochondrial energy metabolism in oral tumorigenesis. Biomedicine (Taipei) (2016) 6(1):3. doi:10.7603/s40681-016-0003-7

31. Lai SW, Lin CL, Liao KF. Risk of contracting pneumonia among patients with predialysis chronic kidney disease: a population-based cohort study in Taiwan. Biomedicine (Taipei) (2017) 7(3):20. doi:10.1051/bmdcn/2017070320

32. Lee MR, Lin C, Lu CC, Kuo SC, Tsao JW, Juan YN, et al. YC-1 induces G0/G1 phase arrest and mitochondria-dependent apoptosis in cisplatin- 
resistant human oral cancer CAR cells. Biomedicine (Taipei) (2017) 7(2):12. doi:10.1051/bmdcn/2017070205

33. Liao KF, Huang PT, Lin CC, Lin CL, Lai SW. Fluvastatin use and risk of acute pancreatitis: a population-based case-control study in Taiwan. Biomedicine (Taipei) (2017) 7(3):24-8. doi:10.1051/bmdcn/2017070317

34. Liu JC, Shen WC, Shih TC, Tsai CW, Chang WS, Cho Y, et al. The current progress and future prospects of personalized radiogenomic cancer study. Biomedicine (Taipei) (2015) 5(1):2. doi:10.7603/s40681-015-0002-0

35. National Health Insurance Research Database. Taiwan. (2017). Available from: http://nhird.nhri.org.tw/en/index.html

36. Lai SW, Chen PC, Liao KF, Muo CH, Lin CC, Sung FC. Risk of hepatocellular carcinoma in diabetic patients and risk reduction associated with antidiabetic therapy: a population-based cohort study. Am J Gastroenterol (2012) 107(1):46-52. doi:10.1038/ajg.2011.384

37. Cheng KC, Chen YL, Lai SW, Tsai PY, Sung FC. Risk of esophagus cancer in diabetes mellitus: a population-based case-control study in Taiwan. BMC Gastroenterol (2012) 12:177. doi:10.1186/1471-230X-12-177

38. Lai SW, Liao KF, Liao CC, Muo CH, Liu CS, Sung FC. Polypharmacy correlates with increased risk for hip fracture in the elderly: a population-based study. Medicine (2010) 89(5):295-9. doi:10.1097/MD.0b013e3181f15efc

39. Liao KF, Lai SW, Li CI, Chen WC. Diabetes mellitus correlates with increased risk of pancreatic cancer: a population-based cohort study in Taiwan. J Gastroenterol Hepatol (2012) 27(4):709-13. doi:10.1111/j.1440-1746.2011. 06938.x

40. Hung SC, Lai SW, Tsai PY, Chen PC, Wu HC, Lin WH, et al. Synergistic interaction of benign prostatic hyperplasia and prostatitis on prostate cancer risk. Br J Cancer (2013) 108(9):1778-83. doi:10.1038/bjc.2013.184

41. Liao KF, Lai SW, Li CI. The impact of anti-diabetic drugs on colorectal cancer risk in a large cohort of women with diabetes. Libyan J Med (2012) 7(10):22. doi:10.3402/ljm.v7i0.17532

42. Lai SW, Lin CL, Liao KF. Use of methimazole and risk of acute pancreatitis: a case-control study in Taiwan. Indian J Pharmacol (2016) 48(2):192-5. doi:10.4103/0253-7613.178841

43. Lai SW. Risks and benefits of zolpidem use in Taiwan: a narrative review. Biomedicine (Taipei) (2016) 6(2):9-11. doi:10.7603/s40681-016-0008-2

44. Hsu FG, Sheu MJ, Lin CL, Hsieh YW, Lai SW. Use of zolpidem and risk of acute pyelonephritis in women: a population-based case-control study in Taiwan. J Clin Pharmacol (2017) 57(3):376-81. doi:10.1002/jcph.815

45. Lin HF, Lai SW, Lin WY, Liu CS, Lin CC, Chang CM. Prevalence and factors of elevated alanine aminotransferase in central Taiwan - a retrospective study. Biomedicine (Taipei) (2016) 6(2):11. doi:10.7603/s40681-0160011-7

46. Mei-Ling S, Kuan-Fu L, Sung-Mao T, Cheng-Li LM, Shih-Wei L. Herpes zoster correlates with pyogenic liver abscesses in Taiwan. Biomedicine (Taipei) (2016) 6(4):22. doi:10.7603/s40681-016-0022-4

47. Liao KF, Cheng KC, Lin CL, Lai SW. Etodolac and the risk of acute pancreatitis. Biomedicine (Taipei) (2017) 7(1):4. doi:10.1051/bmdcn/2017070104

48. Lin HF, Liao K-F, Chang C-M, Lai S-W, Tsai P-Y, Sung FC. Anti-diabetic medication reduces risk of pulmonary tuberculosis in diabetic patients: a population-based cohort study in Taiwan. Kuwait Med J (2017) 49(1):22-8.

49. Cheng KC, Lin WY, Liu CS, Lin CC, Lai HC, Lai SW. Association of different types of liver disease with demographic and clinical factors. Biomedicine (Taipei) (2016) 6(3):16-22. doi:10.7603/s40681-016-0016-2

50. Lai SW, Lin CL, Liao KF, Chen WC. No association between depression and risk of hepatocellular carcinoma in older people in Taiwan. ISRN Psychiatry (2013) 2013:901987. doi:10.1155/2013/901987

51. Liao KF, Cheng KC, Lin CL, Lai SW. Statin use correlates with reduced risk of pyogenic liver abscess: a population-based case-control study. Basic Clin Pharmacol Toxicol (2017) 121(2):144-9. doi:10.1111/bcpt.12777

52. Lin CM, Liao KF, Lin CL, Lai SW. Use of simvastatin and risk of acute pancreatitis: a nationwide case-control study in Taiwan. J Clin Pharmacol (2017) 57(7):918-23. doi:10.1002/jcph.881
53. Cheng KC, Liao KF, Lin CL, Lai SW. Correlation of proton pump inhibitors with pulmonary tuberculosis: a case-control study in Taiwan. Front Pharmacol (2017) 8:481. doi:10.3389/fphar.2017.00481

54. Liao KF, Lin CL, Lai SW. Population-based case-control study assessing the association between statins use and pulmonary tuberculosis in Taiwan. Front Pharmacol (2017) 8:597. doi:10.3389/fphar.2017.00597

55. Lin HF, Liao KF, Chang CM, Lin CL, Lin CH, Lai SW. Use of thiazolidinediones and risk of hip fracture in old people in a case-control study in Taiwan. Medicine (2017) 96(36):e7712. doi:10.1097/MD.0000000000007712

56. Lai SW, Lin CL, Liao KF. Population-based cohort study investigating the correlation of diabetes mellitus with pleural empyema in adults in Taiwan. Medicine (2017) 96(36):e7763. doi:10.1097/MD.0000000000007763

57. Watkins DC, Assari S, Johnson-Lawrence V. Race and ethnic group differences in comorbid major depressive disorder, generalized anxiety disorder, and chronic medical conditions. JRacial Ethn Health Disparities (2015) 2(3):385-94. doi:10.1007/s40615-015-0085-z

58. Herbert TB, Cohen S. Depression and Immunity: A Meta-Analytic Review. Washington, DC: American Psychological Association (1993).

59. Lai SW, Wang IK, Lin CL, Chen HJ, Liao KF. Splenectomy correlates with increased risk of pulmonary tuberculosis: a case-control study in Taiwan. Clin Microbiol Infect (2014) 20(8):764-7. doi:10.1111/1469-0691.12516

60. Lai SW, Lin CL, Liao KF, Tsai SM. Increased risk of pulmonary tuberculosis among patients with appendectomy in Taiwan. Eur J Clin Microbiol Infect Dis (2014) 33(9):1573-7. doi:10.1007/s10096-014-2112-0

61. Issa BA, Yussuf AD, Kuranga SI. Depression comorbidity among patients with tuberculosis in a university teaching hospital outpatient clinic in Nigeria. Ment Health Fam Med (2009) 6(3):133-8.

62. Ige OM, Lasebikan VO. Prevalence of depression in tuberculosis patients in comparison with non-tuberculosis family contacts visiting the DOTS clinic in a Nigerian tertiary care hospital and its correlation with disease pattern. Ment Health Fam Med (2011) 8(4):235-41.

63. Aghanwa H, Erhabor GE. Demographic/socioeconomic factors in mental disorders associated with tuberculosis in southwest Nigeria. JPsychosom Res (1998) 45(4):353-60. doi:10.1016/S0022-3999(98)00006-3

64. Lopez AG. Tuberculosis and the severely mentally ill. Am J Psychiatry (1994) 151(1):151-2.

65. Fullilove MT, Young R, Panzer PG, Muskin P. Psychosocial issues in the management of patients with tuberculosis. JLaw Med Ethics (1993) 21(3-4):324-31. doi:10.1111/j.1748-720X.1993.tb01257.x

66. Panchal S. Correlation with duration and depression in TB patients in rural Jaipur district (NIMS Hospital). Int J Pharm Bio Sci (2011) 2(2):263-7.

67. Blazer D, Williams CD. Epidemiology of dysphoria and depression in an elderly population. Am J Psychiatry (1980) 137(4):439-44.

68. Livingston G, Blizard B, Mann A. Does sleep disturbance predict depression in elderly people? A study in inner London. Br J Gen Pract (1993) 43(376):445-8.

69. Cegielski J, McMurray D. The relationship between malnutrition and tuberculosis: evidence from studies in humans and experimental animals. Int J Tuberc Lung Dis (2004) 8(3):286-98.

70. Rose N, Shang H, Pfyffer GE, Brändli O. Tuberculosis therapy in canton Zurich 1991-1993: what are the causes for recurrence and therapy failure? Schweiz Med Wochenschr (1996) 126(48):2059-67.

Conflict of Interest Statement: The authors declare that the research was conducted in the absence of any commercial or financial relationships that could be construed as a potential conflict of interest.

Copyright $\odot 2017$ Cheng, Liao, Lin and Lai. This is an open-access article distributed under the terms of the Creative Commons Attribution License (CC BY). The use, distribution or reproduction in other forums is permitted, provided the original author(s) or licensor are credited and that the original publication in this journal is cited, in accordance with accepted academic practice. No use, distribution or reproduction is permitted which does not comply with these terms. 